\title{
BIODETERIORO.
}

\section{ALTERACIÓN BIOLÓGICA DE MONUMENTOS Y OBRAS DE ARTE}

\author{
Marta Sameño Puerto \\ Departamento de Análisis \\ del I.A.P.H. \\ Jorge García Rowe \\ Departamento de Biología \\ Vegetal y Ecología. \\ Universidad de Sevilla.
}

Para iniciar la fase de intervención sobre el patrimonio histórico es necesario un conocimiento preliminar de todas las áreas de estudio que ofrezca un determinado bien cultural. Así, cualquier intervención propuesta se justificará por el estado de conservación y las necesidades que requiera la obra de arte. Esto configurará el informe técnico: estudios preliminares, investigación, intervención y mantenimiento.

\section{¿Qué es el biodeterioro?}

Este término ha empezado ha usarse hace tan solo 20 años, pero describe ciertos procesos que han afectado al hombre desde que éste empezó a tener y a usar materiales.

H. J. Hueck (1965, 1968) definió el biodeterioro como "ciertos cambios indeseables en las propiedades de un material causados por la actividad vital de algunos organismos". Otro término usado comúnmente es el de biodegradación que se define igualmente como el proceso de destrucción de un material por organismos vivos o por productos de su metabolismo, si bien la biodegradación puede ser un fenómeno positivo por lo que este término no es usado actualmente por los especialistas.

Desde hace algunos años se vienen publicando diversos estudios relacionados con los aspectos biológicos de la alteración de monumentos, como:

- Bolívar Galiano, F. C. y J. García Rowe (1994). "Biodeterioro en la fuente del claustro principal del hospital de San Juan de Dios (Granada)". Cuad. Art. Gr. $N^{\circ}$ XXV, pp. 197-205.

- Caneva G., G. de Marco y M. A. Pontrandolfi (1993). "Plant communities on the walls of Venosa castle (Basilicata, Italy) as biodetenogens and bioindicators". Conservation of stone and other materials: Vol. I, pp. 263-270.

- García Rowe J. y C. Sáiz Jiménez (|99|). "Colonización y alteración de la piedra por líquenes, briofitos y plantas superiores en las catedrales de Salamanca, Sevilla y Toledo". Jornadas sobre Restauración y Conservación de monumentos. I.C.R.B.C. Ministerio de cultura, pp. 7|-79.

- Nimis, P. L., M. Monte y M. Tretiach (1987). "Flora e vegetazione lichenica di aree archeologiche del Lazio. Roma". Studia Geobotánica, 7, pp. 3-161.

No obstante, en nuestro país se han estudiado escasamente los agentes biológicos causantes de la alte- ración en monumentos y obras de arte, así como los tratamientos biocida para su conservación.

La sola presencia de organismos sobre un material no es suficiente prueba de su biodeterioro, se requiere un cambio evidente en las propiedades de dicho material.

Los materiales pueden sufrir procesos de alteración de tres tipos: físicos, químicos y biológicos. La alteración biológica se debe a la influencia ejercida por organismos vivos: desde algas, líquenes, briofitos (musgos y hepáticas) y plantas superiores, que pueden provocar alteraciones detectables a simple vista, y bacterias y hongos, principalmente actinomiceto, cuya presencia sólo se pone de manifiesto a través de análisis de laboratorio; hasta animales, entre los que se incluye el hombre.

Los fenómenos de biodeterioro más frecuentes son la formación de manchas y eflorescencias producidas por hongos y bacterias respectivamente, formación de pátinas de algas y líquenes y la invasión por briofitos y plantas superiores.

Cualquier obra de arte está sometida a una progresiva destrucción dependiendo de la materia de la que está formada y de las condiciones en las que ha sido conservada. No se puede pasar por alto que muchos de estos objetos están constituidos por celulosa y lignina, o bien se someten a tratamientos con proteínas, ceras, barnices, etc. Todos estos compuestos orgánicos pueden ser utilizados como elementos nutritivos por una gran variedad de microorganismos e insectos.

Por tanto, la presencia de organismos depende de las condiciones climáticas (humedad y temperatura), especialmente las microclimáticas, así como de la presencia de un sustrato nutritivo y de su naturaleza (textura, $\mathrm{pH}$, etc.)

La mayoría de los organismos poseen una gran adaptabilidad metabólica, de manera que lo encontramos en los más diversos objetos de arte esculturas, pinturas, libros, muebles, objetos metálicos, etc.

\section{Bioalteración de la piedra}

El biodeterioro que experimentan los materiales pétreos de edificios, yacimientos arqueológicos y esculturas aumenta progresivamente. Una de las mayores causas de este proceso es la acción de la vegetación infectante. 
Con respecto a las condiciones ambientales, se pueden diferenciar claramente dos tipos de bioalteración en base a la humedad del sustrato: cuando ésta es continua predominan las cianobacterias, algas y briofitos; sin embargo si la humedad no es permanente se observa la presencia de líquenes de biotipo (tipo ecológico) crustáceo, los cuales incrementan la alteración del sustrato.

Existen algunos microorganismos que están relacionados con la degradación de rocas o de edificios y monumentos calcáreos. La corrosión del carbonato cálcico puede atribuirse a una serie de actividades bioquímicas verificadas mediante un examen in vitro tras aislar el microorganismo. La solubilización del material calcáreo puede ser llevada a cabo por una serie de ácidos orgánicos y por otros compuestos orgánicos de estructura química compleja.

\section{Mecanismos de bioalteración}

Los diversos agentes biológicos pueden presentar distintos aspectos y distintos mecanismos de alteración. La presencia de sales solubles (sulfatos y nitratos) en la superficie de la piedra puede ser debida a reacciones químicas (agentes químicos en el aire) o a reacciones enzimáticas de ciertos microorganismos (bacterias del ciclo del azufre y del nitrógeno).

Las algas causan daños meramente estéticos sobre las piedras. Se presentan en forma de polvo y fragmentos minúsculos de diversos colores, en forma de láminas, escamas, costras de coloración verde o negra o como incrustaciones de color negro, blanco o rosa. El alto grado de humedad que poseen las piedras favorece su crecimiento, así como la adherencia de polvo, por lo que se forma una capa o pátina fangosa que puede ser aprovechada por otros organismos y además mantiene la humedad en la superficie de la piedra ayudando a su disolución por agua. Otras algas (endolíticas) pueden corroer y perforar la piedra.

La presencia de superficies corroídas indica un ataque de la piedra por hongos mediante excreción de determinadas sustancias químicas. Además pueden producir manchas superficiales y alteraciones importantes por penetración de las hifas. Por otro lado, los desniveles que causan en la superficie proporcionan nuevos microhabitats para bacterias y algas.

La presencia de los líquenes se manifiesta en forma de polvo y fragmentos, en forma foliácea o de costra y epilíticos o endolíticos. Son organismos de crecimiento lento y con una distribución ecológica muy amplia, son muy resistentes a las condiciones extremas de temperatura y humedad.

Los líquenes causan daños químicos y mecánicos sobre el sustrato que colonizan, mediante la excreción de ácidos orgánicos (el ácido oxálico es el responsable de la quelación de determinadas moléculas de la superficie) y la penetración de las hifas del hongo, así como la alternancia de expansión en estado hidratado y contracción en estado seco. Por otro lado los líquenes pueden constituir una protección contra otros agentes degradativos.

Los briofitos (musgos y hepáticas), generalmente en
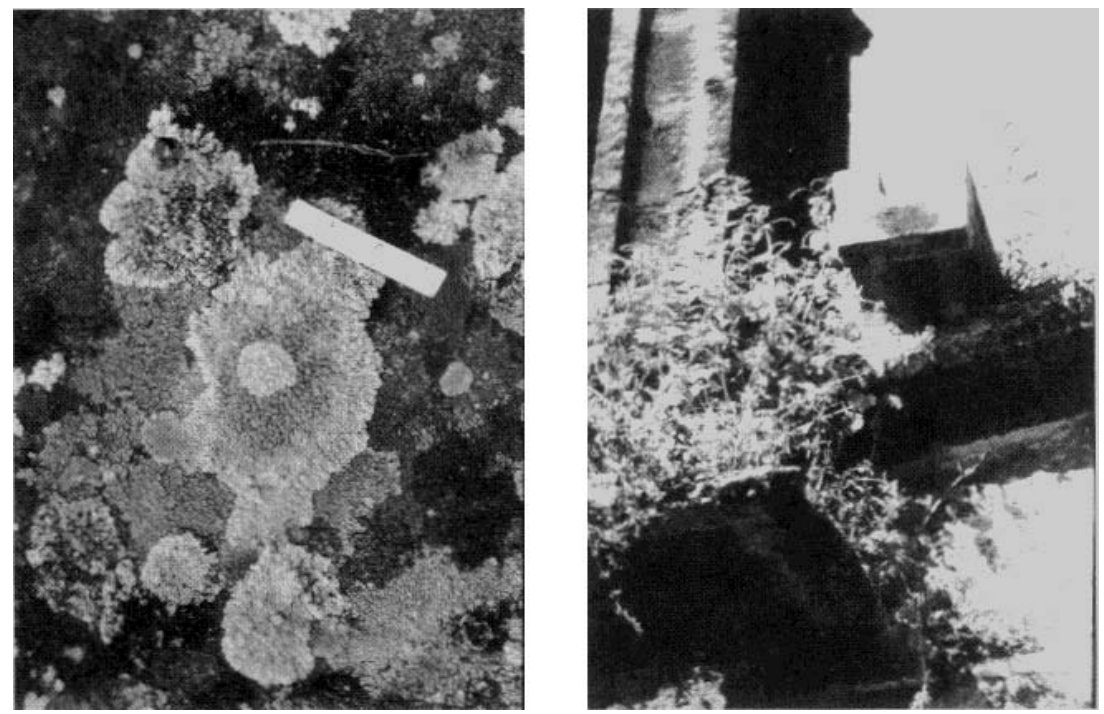

forma de "almohadillas", necesitan depósitos de humus, zonas húmedas y totalmente protegidas. Sus rizoides penetran en la piedra produciendo daños mecánicos.

Otra causa de bioalteración de estructuras monumentales son las plantas superiores. Pueden provocar daños físicos, por penetración de sus raíces en el sustrato, y daños químicos debidos a la actividad de los exudados de sus raíces. Estos exudados digieren el sustrato provocando fisuras en las que penetra el agua que, además de disolver y lavar el material, se congela en invierno rajando y separando porciones de la estructura.

\section{Análisis y determinación}

La alteración biológica de los monumentos pétreos se puede evaluar a través del análisis y la determinación de los organismos presentes. Así pues, se puede recurrir a métodos morfológicos, microbiológicos, bioquímicos, histoquímicos y químicos.

Los métodos morfológicos y estructurales implican varias técnicas de examen del material pétreo: - observación visual;

- estereomicroscópico, aunque de escaso aumento, permite identificar los organismos presentes;

- con microscopio óptico, se puede reconocer la morfología y estructura celular de cada grupo de organismos y microorganismos;

- con microscopio electrónico de barrido, para la observación tridimensional de las células o de la superficie de la piedra;

- con microscopio electrónico de transmisión, para observarlas características ultraestructurales de las células.

En resumen, las superficies pétreas se pueden considerar como un sustrato donde se asientan distintas comunidades, sobre todo cuando no se efectúan trabajos de limpieza y mantenimiento, ni se controla el crecimiento con algún tipo de biocida.

Así pues, el análisis y determinación de la vegetación deben ser considerados como una contribución importante e imprescindible al estudio de tratamientos biocidas para la conservación.

\section{El biodeterioro que experimentan los materiales pétreos de edificios, yacimientos arqueológicos y esculturas aumenta} progresivamente. Una de las mayores causas de este proceso es la acción de la vegetación infectante. 